\title{
Timely Interventions can Increase Smoking Cessation Rate in Men with Ischemic Stroke
}

\author{
Lee, Min Jeong ${ }^{1,2} \cdot$ Park, Eunjeong ${ }^{3} \cdot$ Kim, Hyeon Chang ${ }^{4} \cdot$ Lee, Hye Sun ${ }^{5} \cdot$ Cha, Myoung-Jin $\cdot$ Kim, Young Dae $\cdot$ Heo, Ji Hoe $\cdot$ Nam, Hyo Suk ${ }^{1}$ \\ ${ }^{1}$ Department of Neurology, Yonsei University College of Medicine, Seoul \\ ${ }^{2}$ Division of Nursing, Severance Hospital, Seoul \\ ${ }^{3}$ Department of Cardiovascular Research Institute, Yonsei University College of Medicine, Seoul \\ ${ }^{4}$ Department of Preventive Medicine, Yonsei University College of Medicine, Seoul \\ ${ }^{5}$ Biostatistics Collaboration Unit, (Department of Research Affairs) Yonsei University College of Medicine, Seoul, Korea.
}

\begin{abstract}
Purpose: Smoking cessation is strongly recommended for every smoker after ischemic stroke, but many patients fail to quit smoking. An improved smoking cessation rate has been reported with intensive behavioral therapy during hospitalization and supportive contact after discharge. The aim of this study was to demonstrate the usefulness of the timely interventions for smoking cessation in men with acute ischemic stroke. Methods: Patients who participated in the timely interventions strategy (TI group) were compared with those who received conventional counseling (CC group). In the TI group, a certified nurse provided comprehensive education during admission and additional counseling after discharge. Outcome was measured by point smoking success rate and sustained smoking cessation rate for 12 months. Results: Participants, 157 men (86 of the TI group and 71 of the CC group), were enrolled. Mean age was $58.25 \pm 11.23$ years and mean initial National Institutes of Health Stroke Scale score was 4.68 \pm 5.46 . The TI group showed a higher point smoking success rate compared with the CC group ( $p=.003$ ). Multiple logistic regression analysis showed that the TI group was 2.96 -fold $(95 \% \mathrm{Cl}, 1.43 \sim 6.13)$ more likely to sustain smoking cessation for 12 months than the $\mathrm{CC}$ group. Conclusion: Findings indicate that multiple interventions initiated during hospital stay and regular follow-up after discharge are more effective than conventional smoking cessation counseling in men with acute ischemic stroke.
\end{abstract}

Key words: Smoking cessation; Cerebral infarction; Behavior control; Sex

\section{INTRODUCTION}

Smoking is an established and modifiable risk factor and associated with recurrence in stroke [1,2]. Healthcare providers should strongly advise every stroke patient who has smoked in the past year to quit smoking [2]. People have varying levels of difficulties in physical or psychological aspects to quit smoking. Behavioral interventions including individual or group counseling [3,4], telephone counseling [5,6], and physician advice [7] have been shown to improve the likelihood of smoking cessation. However, absolute cessation rates in stroke patients remain low [8].

Due to the ethical issue, randomized controlled trial for smoking cessation after stroke is almost impossible [9]. Moreover, no observational study has attempted to test the usefulness of a multiple intervention strategy including enhanced counseling during hospitalization and regular follow-up counseling after discharge. The risk associated with smoking is present at all ages,

*This research was supported by a grant of the Korea Health Technology R\&D Project through the Korea Health Industry Development Institute (KHIDI), funded by the Ministry of Health \& Welfare, Republic of Korea (HC15C1056).

Address reprint requests to: Nam, Hyo Suk

Department of Neurology, Yonsei University College of Medicine, 50-1 Yonsei-ro, Seodaemun-gu, Seoul 03722, Korea

Tel: +82-2-2228-1617 Fax: +82-2-393-0705 E-mail: hsnam@yuhs. ac

Received: January 14, 2016 Revised: April 11, 2016 Accepted: May 18, 2016

This is an Open Access article distributed under the terms of the Creative Commons Attribution NoDerivs License. (http://creativecommons. org/licenses/by-nd/4. 0)

If the original work is properly cited and retained without any modification or reproduction, it can be used and re-distributed in any format and medium. 
in both man and women and among different populations [10]. There are gender differences in the prevalence of smoking and success rates in smoking cessation [11]. In this regard, we investigated the effectiveness of a timely intervention (TI) for smoking cessation in men with acute ischemic stroke.

\section{METHODS}

\section{Patients}

This study is a retrospective cohort study comparing before and after intervention periods. The timely interventions initiated during hospitalization were given for TI group, whereas conventional counseling (CC) group did not receive them. For comparison, TI group was compared with CC group. The CC group consisted of the stroke patients who had been admitted consecutively 1 year before the TI period. They were drawn for the same duration of 6 months as TI group.

Current smokers were defined as those who had smoked a cigarette during the 12 months prior to admission. For this study, data pertaining to current smokers with a first-ever stroke were drawn from the Yonsei Stroke Registry. In the Yonsei Stroke Registry, patients with acute ischemic stroke or transient ischemic attack within 7 days after symptom onset were consecutively registered from 1994 [12]. A regular follow-up at outpatient clinic and telephone interviews were conducted by a stroke coordinator nurse and she collected data included the recurrence of vascular events, functional outcome, medication compliance, and newly detected risk factors. Blood pressure, body mass index, abdominal circumference, and body weight were measured. In addition, for smokers, smoking cessation status was also evaluated in each interview.

All patients with stroke were asked about their smoking history. Physicians strongly advised every patient who had smoked to quit. Along with physician advice, a stroke coordinator nurse who had completed a regular course of education for smoking cessation provided comprehensive counseling. The stroke coordinator provided face-to-face education for each patient using a personal tablet computer that contained education materials and movie clips. The contents in tablets were harmfulness of cigarette smoking, strong association between smoking and stroke, benefits after smoking cessation, and coping strategies for withdrawal symptoms after smoking cessation. The education session ran about 20 minutes. The guideline recommended nicotine products and oral medication for smoking cessation to help smokers to quit after ischemic stroke [9,13]. Every patient in the TI group was considered for use of smoking cessation drugs. Smoking cessation medications (bupropion, varenicline tartrate, or nicotine patch) were prescribed according to the physician's decision. After discharge, the stroke coordinator nurse performed telephone counseling for smoking cessation in the TI groupat 1 , 3 , and 6 months. The telephone counseling was provided for 10 minutes. Stroke coordinator asked smoking status. If the patient failed to quit smoking, information on the effect of smoking and various coping strategies for withdrawal symptoms were provided. If the patient was successfully maintaining the quit status, encouragement was provided along with information of the benefits after smoking cessation.

During hospital stay, the CC group patients received conventional recommendation to quit smoking from physicians and a pamphlet from ward nurses. Exclusion criteria for both TIand CC groups were impaired consciousness, communication difficulties (aphasia or cognitive dysfunction), terminal illnesses, deaths during hospitalization, and serious neurological, medical or psychological illness. Patients who refused counseling for smoking cessation or regular follow-up were also excluded. This study was approved by the Severance Hospital Institutional Review Board, Yonsei University Health System and informed consent was waived because of the retrospective and observational nature of the study (4-2011-0635).

\section{Follow-up and Outcome Variable}

Patients in both groups were followed up by independent investigator for smoking status in the same intervals of $1,3,6,9$, and 12 months after discharge. The smoking status was obtained from the patient or proxy during an outpatient clinic or by telephone interviews. Two outcome variables were analyzed in this study. 1) Point smoking success rate at 1, 3, 6, 9, and 12 months after discharge and 2) sustained smoking cessation rate for 12 months. Sustained smoking cessation rate was defined when patients reported no smoking (not even a puff) during a 12 
month period [14].

\section{Statistical Analysis}

Windows SPSS (version 18.0, Chicago, IL, USA) and SAS 9.1 (SAS Institute Inc., Cary, NC) were used for statistical analysis. Time of the first cigarette smoking after waking up and the total number of cigarettes per day were collected and stratified. For categorical variables, the chi-square test was used. Continuous variables were analyzed with the independent samples t- test.

Generalized estimating equations (GEE) models are often used to analyze longitudinal and other correlated response data. Because smoking status may change during follow up, we used the GEE analysis to reveal group effect along with time effect. Point smoking success rate were calculated by GEE models adjusting for correlations within patientsand the use of smoking cessation drugs. Two fixed effects were analyzed in GEE models: 1) the between-subjects effect (groups effect, TI group vs. CC group) and 2) the within-subject effect (time effect, follow-up at 1, 3, 6, 9 and 12 months). Possible differences between the groups throughout the follow-up period were analyzed by time $\mathrm{X}$ group interactions. Kaplan-Meier survival analysis is based on a time to event model, its endpoint is used to predict a time when certain positive events or negative events will occur. Kaplan-Meier survival analysis wasperformed to compare the groups in smoking cessation rate during follow-up periods and the differences were tested with a log-rank test. We used univariate Cox regression analysis to estimate hazard ratios with confidence intervals of smoking cessation rate between groups.

To reveal factors associated with sustained smoking cessation for 12 month, simple logistic regression analyses were conducted for variables of age, initial and discharge NIHSS scores, pack years of smoking, first cigarette in the morning after waking up, daily cigarette consumption, length of hospital stay, smoking cessation medication, and group. Variables with $p<.10$ in the simple logistic regression analysesand smoking cessation medicationswere entered into multiple logistic regression analysis [15]. To avoid multicollinearity between initial and discharge NIHSS scores, only discharge NIHSS scores was analyzed in multiple logistic regression analysis. A p-value less than .05 was considered statistically significant. Odds ratios (OR) and 95\% confi- dence intervals (CIs) were also calculated.

\section{RESULTS}

\section{Patients Selection}

The TI group was drawn from 404 consecutive patients with first-ever acute ischemic stroke or transient ischemic attack and the CC group was drawn from 427 consecutive patients. Among them, a total of 216 patients (26\%) were current smokers (116 patients in the TI period and 100 patients in the CC period). Analysis was limited to men because the prevalence of smoking was too low in women. After excluding 11 women (4 of the TI group and 7 of the CC group), a total of 205 current men smokers were enrolled. In the TI group, 26 patients were further excluded due to refusal of counseling during admission (10 patients), severe neurological deficits (6 patients), deaths during hospitalization (3 patients), severe aphasia (2 patients), and missing data (5 patients). Among the patients in CC period, 22 patients were further excluded due to refusal of quit smoking (12 patients), death during hospitalization (8 patients), severe aphasia (1 patient), and missing data (1 patient). Finally, comparison was conducted with a total of 157 patients, 86 in the TI group and 71 in the $\mathrm{CC}$ group.

\section{Demographic and Baseline Characteristics}

Mean age was $58.25 \pm 11.23$ years. Initial National Institutes of Health Stroke Scale (NIHSS) score was 4.68 \pm 5.46 and discharge NIHSS score was $2.77 \pm 4.27$. Mean smoking years was $34.70 \pm 11.78$ years and number of pack years was $36.92 \pm$ 19.88. Most patients (70.6\%) smoked their first cigarette within 30 minutes after awakening and most of them (61.1\%) smoked 11 to 20 cigarettes per day. Although the mean initial NIHSS score of the TI group was lower than that of the CC group (3.82 \pm 4.79 vs. $5.69 \pm 6.03, \mathrm{t}=2.11, p=.037$ ), the mean discharge NIHSS scores were similar (2.44 \pm 3.75 vs. $3.15 \pm 4.79$, $\mathrm{t}=1.03, p=.304)$. Smoking cessation medication was 10 times more likely to be prescribed in the TI group (14.0\%) than the CC group $(1.4 \%)\left(\chi^{2}=8.06, p=.007\right)$ (Table 1$)$. 
Table 1. Patient Characteristics in the Conventional Counseling Group and the Timely Intervention Group

\begin{tabular}{|c|c|c|c|c|c|}
\hline \multirow[t]{2}{*}{ Variables } & \multirow[t]{2}{*}{ Categories } & \multirow{2}{*}{$\begin{array}{l}\text { Conventional counseling } \\
\text { group }(n=71) \\
n(\%) \text { or } M \pm S D\end{array}$} & \multirow{2}{*}{$\begin{array}{l}\text { Timely interventions } \\
\text { group }(n=86) \\
n(\%) \text { or } M \pm S D\end{array}$} & \multirow[t]{2}{*}{$\chi^{2}$ or $t$} & \multirow[t]{2}{*}{$p$} \\
\hline & & & & & \\
\hline Age (year) & & $57.11 \pm 11.39$ & $59.20 \pm 11.07$ & -1.16 & .248 \\
\hline Initial NIHSS score & & $5.69 \pm 6.03$ & $3.82 \pm 4.79$ & 2.11 & .037 \\
\hline Discharge NIHSS score & & $3.15 \pm 4.79$ & $2.44 \pm 3.75$ & 1.03 & .304 \\
\hline Packs & & $1.03 \pm 0.44$ & $1.13 \pm 0.58$ & -1.19 & .238 \\
\hline Years & & $34.25 \pm 11.73$ & $35.07 \pm 11.87$ & -0.43 & .667 \\
\hline Pack years & & $34.38 \pm 16.99$ & $39.03 \pm 21.86$ & -1.45 & .145 \\
\hline $\begin{array}{l}\text { First cigarette of the day after waking-up } \\
(\min )^{\star}\end{array}$ & $\begin{array}{l}<5 \\
5 \sim 30 \\
31 \sim 60 \\
>60\end{array}$ & $\begin{aligned} 30 & (49.2) \\
9 & (15.80) \\
17 & (29.8) \\
2 & (3.5)\end{aligned}$ & $\begin{array}{l}48(55.2) \\
15(17.4) \\
23(26.7) \\
0(0)\end{array}$ & 3.35 & .341 \\
\hline Cigarettes per day & $\begin{array}{l}<10 \\
11 \sim 20 \\
21 \sim 30 \\
>30\end{array}$ & $\begin{aligned} 4 & (5.6) \\
50 & (70.4) \\
9 & (12.7) \\
8 & (11.3)\end{aligned}$ & $\begin{array}{l}8(9.3) \\
46(53.5) \\
12(14.0) \\
20(23.3)\end{array}$ & 0.57 & .128 \\
\hline Length of hospitalization (days)* & & $8(6 \sim 11)$ & $7(6 \sim 11)$ & & .479 \\
\hline smoking cessation medication users $^{\dagger}$ & & $1(1.4)$ & $12(14.0)$ & 8.06 & .007 \\
\hline
\end{tabular}

NIHSS: National Institutes of Health Stroke Scale; * Data of 41 patients of the conventional counselling group are missing, values are median (25 percentile 75 percentile); 'Smoking cessation medication includes bupropion, varenicline tartrate, and nicotine patch.

\section{Point Smoking Cessation Rates}

After discharge, most failures occurred within 1month. The early failure rates within one month in the TI group (20.9\%) were significantly lower than the CC group (42.3\%) $\left(x^{2}=8.33\right.$, $p<.001)$. Point smoking cessation rate in all study patients were $69.4 \%, 65.0 \%, 63.1 \%, 64.3 \%$, and $65.6 \%$ at $1,3,6,9$, and 12 months, respectively. In the TI group,point smoking Cessation rateswere $79.1 \%, 74.4 \%, 75.6 \%, 72.1 \%$, and $70.9 \%$, whereas in the CC group, that were 57.7\%, 53.5\%, 47.9\%, 54.9\%, and $59.2 \%$ at $1,3,6,9$, and 12 months, respectively.

The GEE analysis was undertaken to estimate time effect on point smoking cessation rate. Borderline significance was found in the interaction between groups and the follow-up period $(p=.138)$. The GEE analysis showed significant group effect (TI group vs. CC group) on smoking cessation rate $(p=.002)$. In contrast, follow-up period $(p=.064)$ and smoking cessation drugs $(p=.604)$ were not significant (Table 2). Comparing each follow-up period, the TI group showed higher estimated point smoking cessation rate compared with the CC group, except at 12 months ( $p=.002$ at 1 month, $p=.003$ at 3 months, $p<.001$ at 6 months, $p=.014$ at 9 months, and $p=.067$ at 12 months)
(Figure 1). The Kaplan-Meier analysis revealed that the TI group was 2.17-fold (95\% CI, 1.30 3.60) more likely to be successful in smoking cessation than the CC group (Figure 2).

\section{Sustained Smoking Cessation Rate for 12 Months}

Patients who received TI strategy were more likely to be sustain smoking cessation for 12 months comparing with the CC group (66.3\% vs. $46.5 \%, x^{2}=6.23, p=.015$ ). In simple logistic regression analysis, factors associated with sustained smoking cessation rate for 12 months were older age, higher initial and discharge NIHSS scores, and longer hospital stay. Multiple logistic regression analysis showed that the TI group and stroke severity at discharge were independent predictors of sustained smoking cessation for 12 months. The patients of TI group were 2.96 -fold (95\% CI, 1.43 6.13) more likely to be sustained smoking cessation than those of the CC group (Table 3).

\section{DISCUSSION}

In this study, we found that timely provided interventions for smoking cessation were more effective than conventional coun- 


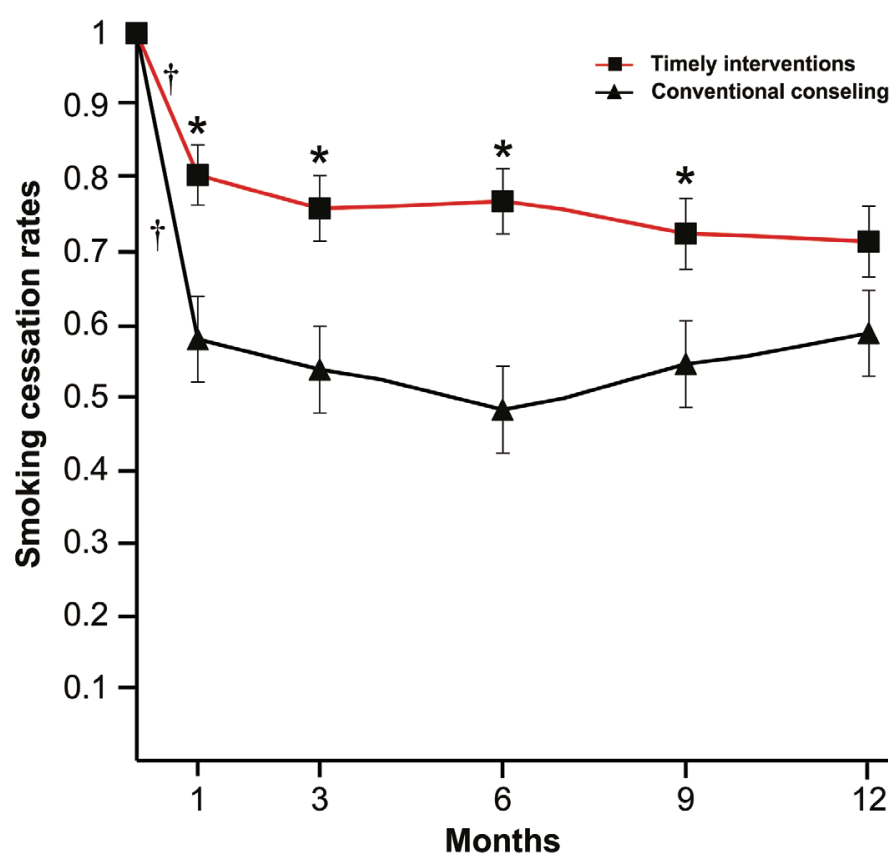

" $p<.05$ compared with the conventional counseling group;

${ }^{\dagger} p<.05$ compared between discharge and 1 month.

Figure 1. Estimated smoking cessation rates between the timely interventions and the conventional counseling groups.

Success rate in smoking cessation were compared using generalized estimating equation model. At each follow-up period, the timely interventions group showed significantly higher estimated smoking cessation rate compared with the conventional counseling group $\left(^{*}\right)$, except at 12 months. Most failure occurred during the first month after discharge in both groups $\left(^{\dagger}\right)$. Error bars are standard errors of estimated smoking cessation rates.

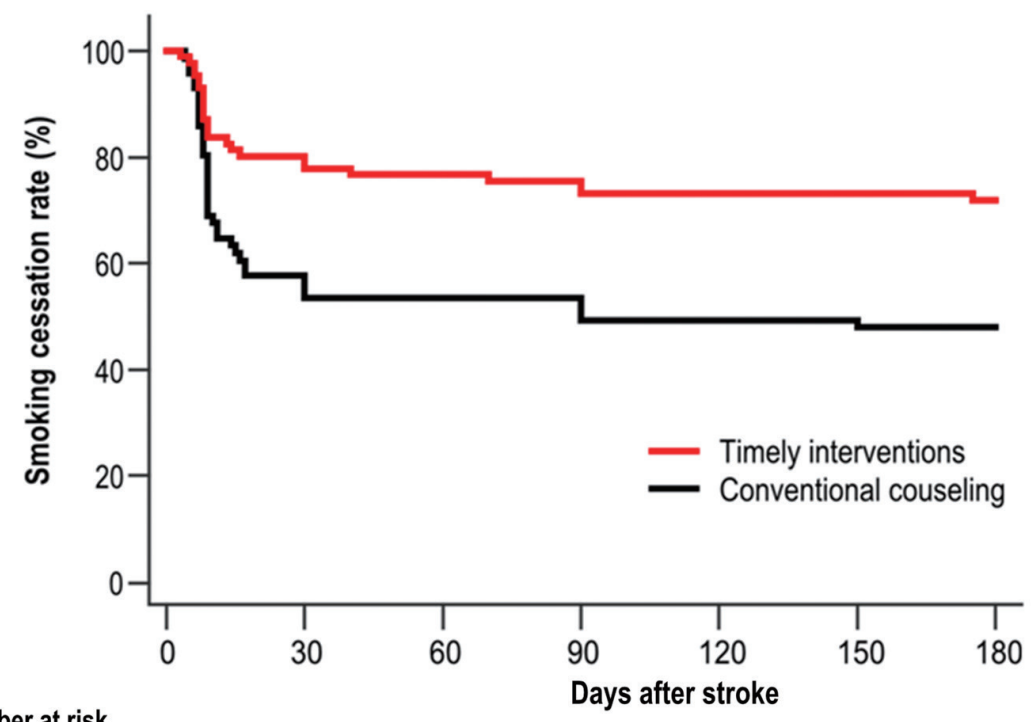

Number at risk

Days after stroke

$\begin{array}{llllllll}\text { Timely interventions } & 86 & 66 & 65 & 62 & 60 & 60 & 58 \\ \text { Conventional couseling } & 71 & 38 & 38 & 35 & 35 & 34 & 34\end{array}$

Figure 2. Kaplan-Meier survival analysis between the timely interventions group and the conventional counseling group.

The timely interventions group showed higher likely to be successful in smoking cessation during follow-up compared to the conventional counseling group (log-rank test, $p=.002$, hazard ratio 2.17, $95 \% \mathrm{Cl}, 1.30 \sim 3.60$ ). 
Table 2. Generalized Estimating Equation Models for Smoking Cessation Rates

\begin{tabular}{|c|c|c|c|c|}
\hline \multirow{2}{*}{ Time (months) } & \multicolumn{2}{|c|}{ Point smoking cessation rate $(95 \% \mathrm{Cl})$} & \multirow{2}{*}{ Overall $p$} & \multirow{2}{*}{$\begin{array}{c}\text { Post-hoc } \\
\text { analysis }\end{array}$} \\
\hline & Timely interventions & Conventional counseling & & \\
\hline $\begin{array}{l}1 \\
3 \\
6 \\
9 \\
12\end{array}$ & $\begin{array}{l}0.81(0.73 \sim 0.89) \\
0.77(0.68 \sim 0.85) \\
0.77(0.69 \sim 0.86) \\
0.73(0.63 \sim 0.82) \\
0.72(0.62 \sim 0.81)\end{array}$ & $\begin{array}{l}0.59(0.48 \sim 0.70) \\
0.55(0.44 \sim 0.66) \\
0.49(0.38 \sim 0.60) \\
0.54(0.43 \sim 0.66) \\
0.58(0.47 \sim 0.69)\end{array}$ & $\begin{array}{c}\text { Group: } .002 \\
\text { Time: } .064 \\
\text { Group X Time: } .138 \\
\text { Medications: } .604\end{array}$ & $\begin{array}{r}.002 \\
.003 \\
<.001 \\
.014 \\
.067\end{array}$ \\
\hline
\end{tabular}

Table 3. Simple and Multiple Logistic Regression Analyses of Sustained Smoking Cessation for 12 Months

\begin{tabular}{|c|c|c|c|c|c|}
\hline \multirow{2}{*}{ Variables } & \multirow{2}{*}{ Categories } & \multicolumn{2}{|c|}{ Simple logistic regression analysis } & \multicolumn{2}{|c|}{ Multiple logistic regression analysis } \\
\hline & & OR $(95 \% \mathrm{Cl})$ & $p$ & OR $(95 \% \mathrm{Cl})$ & $p$ \\
\hline \multicolumn{2}{|l|}{ Age (year) } & $1.03(1.00 \sim 1.06)$ & .041 & $1.02(0.98 \sim 1.05)$ & .314 \\
\hline \multicolumn{2}{|l|}{ Initial NIHSS score } & $1.09(1.02 \sim 1.16)$ & .015 & & \\
\hline \multicolumn{2}{|l|}{ Discharge NIHSS score } & $1.24(1.09 \sim 1.41)$ & .002 & $1.22(1.06 \sim 1.41)$ & $<.001$ \\
\hline \multicolumn{2}{|l|}{ Packs } & $0.61(0.33 \sim 1.13)$ & .113 & & \\
\hline \multicolumn{2}{|l|}{ Years } & $1.01(0.99 \sim 1.04)$ & .379 & & \\
\hline \multicolumn{2}{|l|}{ Pack years } & $1.00(0.98 \sim 1.01)$ & .552 & & \\
\hline $\begin{array}{l}\text { First cigarette of the day after } \\
\text { waking-up (min) }\end{array}$ & $\begin{array}{l}<5 \\
5 \sim 30 \\
31 \sim 60 \\
>60\end{array}$ & $\begin{array}{c}1 \\
1.67(0.10 \sim 28.66) \\
1.4(0.08 \sim 25.14) \\
1.41(0.09 \sim 23.33)\end{array}$ & $\begin{array}{l}.725 \\
.819 \\
.812\end{array}$ & & \\
\hline Cigarettes per day & $\begin{array}{l}<10 \\
11 \sim 20 \\
21 \sim 30 \\
>30\end{array}$ & $\begin{array}{c}1 \\
0.7(0.20 \sim 2.49) \\
0.55(0.13 \sim 2.4) \\
0.43(0.11 \sim 1.78)\end{array}$ & $\begin{array}{l}.581 \\
.427 \\
.246\end{array}$ & & \\
\hline \multicolumn{2}{|l|}{ Length of hospitalization* } & $8.02(1.88 \sim 34.17)$ & .005 & $2.32(0.36 \sim 14.92)$ & .376 \\
\hline \multicolumn{2}{|c|}{ Smoking cessation medication users } & $1.28(0.40 \sim 4.10)$ & .678 & $1.60(0.48 \sim 5.35)$ & .445 \\
\hline \multicolumn{2}{|l|}{ Timely interventions group } & $2.28(1.19 \sim 4.33)$ & .012 & $2.96(1.43 \sim 6.13)$ & $<.001$ \\
\hline
\end{tabular}

OR=Odds ratio; $\mathrm{Cl}=$ Confidence interval; NIHSS=National Institutes of Health Stroke Scale; *log-Transformation Data

seling in terms of point cessation and sustained smoking cessation rate for 12 months. Point smoking success rates in TI group at 3,6 , and 12 months were $74.4 \%, 75.6 \%$, and $70.9 \%$, respectively. These success rates were higher than those reported by previous studies, of $28 \sim 43 \%$ at 3 months $[8,16], 22 \sim 36 \%$ at 6 months [15,17], and 36 41\% at 12 months after stroke $[16,18]$. However, these differences may be related topatient characteristics (socio-economic, gender, or ethnic differences), variation in study design (intensity of intervention, follow-up interval, or sample size), and the year of study.

Behavioral interventions that begin during hospital stay can increase the smoking cessation rate [19-21]. Because most smokers attempt to quit after experiencing a stroke [14], the optimal time for smoking cessation is soon after the stroke because smoking-related health events can be a teachable moment [22]. In this study, both the TI and the CC group had received conventional education for smoking cessation during hospital stay. Along with the conventional counseling, patients in the TI group received a comprehensive education by a certified nurse during admission and after discharge. The TI strategy administered by a dedicated counselor ("assist") and prevention of relapse by a telephone interview ("arrange") can increase the long-term success rate after hospital discharge [23]. Moreover, the Cochrane review showed that nursing-delivered smoking cessation interventions were effective. The effectiveness was weaker when the nurse's main role was not smoking cessation and interventions 
were provided over a short period [24]. Because the stroke coordinator in this study had multiple roles, further studies with a full time counseling nurse might increase the smoking cessation rate.

Tobacco dependence is a chronic disease that often requires repeated interventions and multiple attempts to quit [2]. Although majority of smokers attempt to quit smoking after experiencing a stroke, a small number of patients achieves long-term sustained smoking cessation. Duration of interventions was crucial for sustained smoking cession in a previous study [25]. During the CC period, we collected adherence to smoking cessation data for patients who were without counseling after discharge. Whereas, in the TI period, we additionally performed proactive telephone interviews at 1,3 , and 6 months after hospital discharge to prevent failure in smoking cessation. Considering failure rate of the TI group was increased between 6 and 12 months, longer periods of stroke counseling are more likely to achieve sustained smoking cessation.

Smoking cessation is a dynamic process [26]. Our study showed that most failures occurred within the first month after discharge. Patients who failed at 1 month were more likely to be smoking at 12 months. In contrast, patients who succeeded at 1 month were less likely to be smoking at 12 months. This finding indicates that the first month after discharge is the most important time period for sustained smoking cessation. A previous study also showed that counseling that began in the hospital but was associated with less than one month of supportive counseling after discharge, lost its benefit [19]. Soon after discharge, patients return to their previous lives and are exposed to a different environment from that of their hospital stay. Therefore, patients are more likely to fail smoking cessation after discharge. In this regards, follow-up counseling after discharge appears to be one of key components for an effective intervention [19].

This study has several limitations. First, this was not a randomized controlled study. Although different characteristics may influence the results, we recruited the consecutive patients from a prospectively registered stroke database and demographic characteristics were quite similar. Second, a temporal trend of smoking cessation in the population may influence the rate of smoking cessation. In Korea, the smoking rate has decreased over the last decades. Third, while several effective medications are available for tobacco dependence [27], this study did not system- atically test the effectiveness of smoking cessation drugs in conjunction with behavioral counseling. Prescription rates of smoking cessation drugs in the TI group were ten times higher than that of the CC group. Use of smoking cessation drugs did not influence sustained smoking cessation in multiple logistic regression analysis. Further study testing timely provided counseling in conjunction with smoking cessation drugs might be more effective. Fourth, we relied upon self or proxy reports of smoking status. However, the validity of self-reported smoking status has been regarded as acceptable in other observational studies [14].

\section{CONCLUSION}

In this study, we demonstrated that timely counseling for smoking cessation during the hospital stay and regular counseling after discharge were more effective than conventional counseling for men with acute ischemic stroke. Most failures occurred during the first month after discharge. More sophisticated approaches using multiple intensive interventions initiated during hospital stay and maintaining a support for a longer time period after discharge might increase smoking cessation rates.

\section{CONFLICTS OF INTEREST}

The authors declared no conflict of interest.

\section{REFERENCES}

1. Lee JH, Lee JY, Ahn SH, Jang MU, Oh MS, Kim CH, et al. Smoking is not a good prognostic factor following first-ever acute ischemic stroke. Journal of Stroke. 2015;17(2):177-191. http://dx. doi. org/10. 5853/jos. 2015. 17.2. 177

2. Furie KL, Kasner SE, Adams RJ, Albers GW, Bush RL, Fagan $\mathrm{SC}$, et al. Guidelines for the prevention of stroke in patients with stroke or transient ischemic attack: A guideline for healthcare professionals from the American Heart Association/American Stroke Association. Stroke. 2011;42(1):227-276. http://dx. doi. org/10. 1161/STR. 0b013e3181f7d043

3. Lancaster T, Stead LF. Individual behavioural counselling for smoking cessation. The Cochrane Database of Systematic Reviews. 2005;2:CD001292. http://dx. doi. org/10. 1002/14651858. cd001292

4. Stead LF, Lancaster T. Group behaviour therapy programmes for smoking cessation. The Cochrane Database of Systematic Re- 
views. 2005;2:CD001007. http://dx. doi. org/10. 1002/14651858. CD001007. pub2

5. Stead LF, Perera R, Lancaster T. Telephone counselling for smoking cessation. The Cochrane Database of Systematic Reviews. 2006;3:CD002850.

http://dx. doi. org/10. 1002/14651858. CD002850. pub2

6. Kim H, Kim O. The lifestyle modification coaching program for secondary stroke prevention. Journal of Korean Academy of Nursing. 2013;43(3):331-340. http://dx. doi. org/10. 4040/jkan. 2013. 43. 3. 331

7. Stead LF, Bergson G, Lancaster T. Physician advice for smoking cessation. The Cochrane Database of Systematic Reviews. 2008;2 :CD000165. http://dx. doi. org/10. 1002/14651858. CD000165. pub3

8. Sauerbeck LR, Khoury JC, Woo D, Kissela BM, Moomaw CJ, Broderick JP. Smoking cessation after stroke: Education and its effect on behavior. The Journal of Neuroscience Nursing. 2005;37 (6) :316-319, 325.

9. Sacco RL, Adams R, Albers G, Alberts MJ, Benavente O, Furie K, et al. Guidelines for prevention of stroke in patients with ischemic stroke or transient ischemic attack: A statement for healthcare professionals from the American Heart Association/American Stroke Association Council on Stroke: Co-sponsored by the Council on Cardiovascular Radiology and Intervention: The American Academy of Neurology affirms the value of this guideline. Stroke. 2006;37(2):577-617. http://dx. doi. org/10. 1161/01. str. 0000199147. 30016. 74

10. Oh SM, Stefani KM, Kim HC. Development and application of chronic disease risk prediction models. Yonsei Medical Journal. 2014;55(4):853-860. http://dx. doi. org/10. 3349/ymj. 2014. 55. 4. 853

11. Stringhini S, Spencer B, Marques-Vidal P, Waeber G, Vollenweider $\mathrm{P}$, Paccaud F, et al. Age and gender differences in the social patterning of cardiovascular risk factors in Switzerland: The CoLaus study. PLoS One. 2012;7(11):e49443.

http://dx. doi. org/10. 1371/journal. pone. 0049443

12. Lee BI, Nam HS, Heo JH, Kim DI. Yonsei stroke registry. Analysis of 1,000 patients with acute cerebral infarctions. Cerebrovascular Diseases. 2001;12(3):145-151.

http://dx. doi. org/10. 1159/000047697

13. Kernan WN, Ovbiagele B, Black HR, Bravata DM, Chimowitz MI, Ezekowitz MD, et al. Guidelines for the prevention of stroke in patients with stroke and transient ischemic attack: A guideline for healthcare professionals from the American Heart Association/ American Stroke Association. Stroke. 2014;45(7):2160-2236. http://dx. doi. org/10.1161/str. 0000000000000024

14. Ives SP, Heuschmann PU, Wolfe CD, Redfern J. Patterns of smoking cessation in the first 3 years after stroke: The South London stroke register. European Journal of Cardiovascular Prevention and Rehabilitation. 2008;15(3):329-335. http://dx. doi. org/10. 1097/HJR. 0b013e3282f37a58

15. Bruce N, Pope D, Stanistreet D. Quantitative methods for health research: a practical interactive guide to epidemiology and statistics: Wiley; 2013. p. 293.
16. Redfern J, McKevitt C, Dundas R, Rudd AG, Wolfe CD. Behavioral risk factor prevalence and lifestyle change after stroke: A prospective study. Stroke. 2000;31(8):1877-1881. http://dx. doi. org/10. 1161/01. STR. 31. 8. 1877

17. Bak S, Sindrup SH, Alslev T, Kristensen O, Christensen K, Gaist D. Cessation of smoking after first-ever stroke: A follow-up study. Stroke. 2002;33(9):2263-2269. http://dx. doi. org/10. 1161/01. STR. 0000027210. 50936. D0

18. Sappok T, Faulstich A, Stuckert E, Kruck H, Marx P, Koennecke HC. Compliance with secondary prevention of ischemic stroke: A prospective evaluation. Stroke. 2001;32(8):1884-1889. http://dx. doi. org/10. 1161/01. STR. 32. 8. 1884

19. Rigotti NA, Munafo MR, Stead LF. Interventions for smoking cessation in hospitalised patients. The Cochrane Database of Systematic Reviews. 2007;3:CD001837. http://dx. doi. org/10. 1002/14651858. CD001837. pub2

20. Fiore MC, Jaén CR, Baker TB, Bailey WC, Benowitz N, Curry SJ, et al. Treating tobacco use and dependence: 2008 update. Quick reference guide for clinicians [Internet]. Rockville, MD: U. S. Department of Health \& Human Services; 2008 [cited 2016 January 1]. Available from:

http://www. ahrq. gov/professionals/clinicians-providers/guidelinesrecommendations/tobacco/clinicians/references/quickref/index. html.

21. Ovbiagele B, Kidwell CS, Selco S, Razinia T, Saver JL. Treatment adherence rates one year after initiation of a systematic hospital-based stroke prevention program. Cerebrovascular Diseases. 2005;20(4):280-282. http://dx. doi. org/10. 1159/000087711

22. McBride CM, Emmons KM, Lipkus IM. Understanding the potential of teachable moments: The case of smoking cessation. Health Education Research. 2003;18(2):156-170.

23. France EK, Glasgow RE, Marcus AC. Smoking cessation interventions among hospitalized patients: What have we learned? Preventive Medicine. 2001;32(4):376-388. http://dx. doi. org/10. 1006/pmed. 2000. 0824

24. Rice VH, Stead LF. Nursing interventions for smoking cessation. The Cochrane Database of Systematic Reviews. 2008;1: CD001188. http://dx. doi. org/10. 1002/14651858. CD001188. pub3

25. Schuck K, Otten R, Kleinjan M, Bricker JB, Engels RC. Effectiveness of proactive telephone counselling for smoking cessation in parents: Study protocol of a randomized controlled trial. BMC Public Health. 2011;11:732. http://dx. doi. org/10. 1186/1471-2458-11-732

26. Zhou X, Nonnemaker J, Sherrill B, Gilsenan AW, Coste F, West R. Attempts to quit smoking and relapse: Factors associated with success or failure from the ATTEMPT cohort study. Addictive Behaviors. 2009;34(4):365-373.

http://dx. doi. org/10. 1016/j. addbeh. 2008. 11. 013

27. McRobbie H, Hajek P. Nicotine replacement therapy in patients with cardiovascular disease: Guidelines for health professionals. Addiction. 2001;96(11):1547-1551. http://dx. doi. org/10. 1080/09652140120080688 